\title{
PROBLEMAS DE LO NON FINITO EN EL ARTE MEXICANO: SOBRE UNA CABEZA TOTONACA DEL MUSEO ANTROPOLÓGICO DE JALAPA, MÉXICO
}

Claude Gandelman Ben Gurion University

La obra clásica sobre el problema de lo non finito, es decir, de lo intencionalmente no terminado en arte, es sin duda Das Unvollendete als Künstlerische Form (Francke Verlag, Berna y Munich, 1959) y que de hecho es el Acta de un simposio que con el mismo título se celebró en Saarbrücken en 1958, en el que participaron famosos historiadores del arte como Joseph Gantner, Dagobert Frey, Schmoll Gennant Eisenwerth, André Chastel y otros.

Uno de los defectos de esta antología, probablemente la más exhaustiva y seminal que se haya publicado sobre el tema de lo non finito, es que trata este fenómeno sólo dentro del arte en Occidente, pues se concentra en una serie de ejemplos clásicos que abarcan desde Miguel Angel, pasando por Rembrandt, hasta Rodin y Cézanne.

Otra publicación que apareció el mismo año sobre este tema, trató de remediar este defecto de alguna manera. La revista $D u$ (218, abril 1959), publicó entre otros ensayos un artículo de Arpag Mekhitarian titulado: "Unvollständige Darstellungen auf Mauern ägyptischer Tempel un Gräber", en el cual el autor examina un relieve non finito que se localiza en el templo de Amenofis III en el desierto El Kab. Tenemos aquí un tipo de non finito que se remonta a los siglos xI a xIV a. C. y que no pertenece al dominio del arte occidental.

Siguiendo los pasos de Mekhitarian, me gustaría presentar otro ejemplo "exótico" de arte inconcluso, una cabeza totonaca esculpida que se encuentra en el Museo Antropológico de Jalapa. Hallada en el área de El Tajín, es decir en el área cultural totonaca, puede situarse en el periodo que abarca entre los siglos xuI y xvi de nuestra era (figura i). Por lo que he podido averiguar, no ha sido, todavía, objeto de un estudio científico. ${ }^{1}$

Antes de emprender el examen específico de esta cabeza non finito

1 Dos años después de haber terminado este artículo encontré que mi cabeza totonaca era el tema de dos estudios científicos mexicanos Véase infra, $\mathbf{n} .3$ ). 
de México, quisiera volver un momento a las cuestiones teóricas levantadas por el simposio Unvollendete.

En primer lugar desearía aclarar desde el principio, que por non finito los especialistas en el simposio no se referían a una no terminación accidental sino por el contrario, al no acabamiento intencional de las obras de arte. Esta es la premisa sobre la que se apoyan tanto Das Unvollendete als künstlerische Form, cuanto el artículo presente.

En segundo, me gustaría señalar fallas en los hallazgos de los especialistas del Unvollendete, fallas que se deben una vez más, al hecho de haber pasado por alto ejemplos de los objetos non finito extraños al ámbito occidental.

Por ejemplo, los estudios en Das Unvollendete, tanto como en $D u$ se concentran sobre todo en motivaciones del orden estéticofilosófico, es decir, especialmente en el neoplatonismo del Renacimiento y tienden a pasar por algo las motivaciones del orden dogmático-religioso, es decir, formas non finito bien como expresión de un dogma específico o bien como recurso usado para subvertir un dogma religioso.

Nuestra cabeza totonaca pertenece, como lo veremos dentro de poco, a la primera categoría.

Por lo que se refiere a la segunda, el caracter non finito como medio para subvertir un dogma religioso, daré un ejemplo que se deriva de la "iconoclasia" judía y que se relaciona con antiguos procedimientos judios para suprimir el carácter idolátrico de las esculturas paganas.

En el tratado talmúdico llamado Avoda Zara, consagrado a examinar las relaciones de los judios con objetos de culto idolátricos, y en particular, a hacer cumplir con la prohibición de las imágenes, leemos sobre las técnicas para "anular ídolos":

"Mishna ¿Como anula el judío [al ídolo]? Si le cortara la punta de la oreja, la punta de la nariz o la punta del dedo; o incluso si la desfigurara, aunque no hubiera reducción en la cantidad de material..."2

Tenemos aquí, por supuesto, la descripción de lo non finito en cuanto prácticas iconoclastas. Pero supongamos que los artistas judíos de los tiempos antiguos, $\mathrm{y}$ hay muchas excepciones a la prohibición mosaica de las imágenes y una gran cantidad de obras de arte judías

2 The Minor Tractates of the Talmud, traducido al inglés con glosario e indices, bajo la revisión del Rev. doctor A. Cohen (The Sacino Press, Londres 1971) $52 \mathrm{~b}-53 \mathrm{a}$. 
antiguas que representan cuerpos humanos en los mosaicos de la sinagoga Beit Alpha a los frescos de la Dura Europos, estaban al tanto de estas técnicas y representaban los cuerpos humanos como lo hacian, precisamente porque en un punto determinado introducían una señal non finito que aseguraba el carácter kosher de sus obras $\mathrm{y}$, en consecuencia su supervivencia. ¿Es que los frescos de Dura Europos no presentan señales de técnicas non finito? ¿Qué no son los mosaicos de Beit Alpha, con su carácter "infantil" (tal vez "seudo-infantil") una especie de "non finito" judío? Quisiera proponer que se reexaminen las famosas "excepciones" a la prohibición mosaica de las imágenes a la luz de esta hipótesis de non finito "kosherizante".

Naturalmente que lo mismo se aplica a la iconoclasia cristiana. ¿No es posible que bajo el dominio de los iconoclastas algunos artistas bizantinos hayan "integrado" aspectos non finito en sus obras para preservarlas de la destrucción? Estas son cuestiones que seguramente no surgieron durante el simposio Unvollendete.

Como dije antes, nuestra cabeza totonaca de Jalapa, probablemente pertenece al primer tipo: la representación de un dogma religioso. Como lo indica la inscripción didáctica de la pieza, la cabeza "impresiona como una escultura no concluida: pero el artista la terminó deliberadamente así, para dar la impresión de lo que está vivo y lo muerto, de la luz y de la obscuridad, de lo bueno y lo malo". ${ }^{8}$

3 Dos autores que no pude consultar en el momento de la composición del pre. sente artículo, llegaron a conclusiones semejantes respecto al carácter non finito de la cabeza de Jalapa. El primer estudio es de Eduardo Matos Moctezuma, "Parálisis facial prehispánica", México (Instituto Nacional de Antropología e Historia, 1970) 31, en el que el autor escribe en lo tocante a nuestra cabeza: "Escultura hecha en piedra que representa una cara cuya mitad izquierda aparentemente no se terminó; sin embargo en el lado derecho de la cara se ve que la boca está ligeramente des. riada hacia ese lado, notándose el surco que la rodea claramente. E1 lado izquierdo aunque no trabajado de la misma manera, está pulido, lo que parece indicar que el artista quiso hacer así la pieza." E. Matos Moctezuma ve en la cabeza una posible representación de parálisis facial.

El segundo estudio con el que me topé dos años después de escribir mi artículo, puede encontrarse en el número 173 de la revista Artes de México, número dedicado a "La dualidad en el mundo perhispánico". "Mi" cabeza está reproducida como la figura 169 en la sección titulada "Máscaras de vida y muerte". El editor deł número, Wiltraud Zehnder agregó un breve comentario en el sentido de que consi dera la interpretación non finito como la correcta: "... en controversia con muchas opiniones declarantes de que esta escultura es accidental o no terminada", ella ve en la cabeza "una maravillosa manifestación del concepto de la dualidad". Referente al argumento del carácter accidental de la escultura escribe: "Vale señalar que la 
De hecho el non finito se usa aqui para lograr una representación de dualismo religioso.

Como es bien sabido, el dualismo es esencial a la religión de los pueblos del altiplano de México y está encarnado, principalmente en la persona del dios Quetzalcóatl, quien -a pesar de que se sabe tan poco de la religión de los totonacas, ${ }^{4}$ la mayor parte de los autores coinciden en esto- fue importado a la esfera religiosa totonaca y llegó a ser una de sus deidades primordiales.

Quetzalcóatl es un dios dual quien emanó de una región cósmica desconocida llamada la "región de la dualidad" y es llamado "el señor de la dualidad". Pero su dualismo esencial parece proyectarse a la es. fera de lo humano. El hombre azteca y el hombre totonaca son por lo tanto "duales".

Así, un huehuetlatolli, o "discurso de los ancianos", que los nahuas dirigían a los recién nacidos, proclama:

Te has fatigado, te has afanado;

fuiste forjado en el lugar de la dualidad, más allá de los nueve travesaños celestes.

Te forjó, te labró, tu Madre, tu Padre, el Señor y la Señora de la Dualidad

parte izquierda de ninguna manera está 'sin acabar'. Se encuentra completamente terminada; la superficie fue minuciosamente tallada con un conocimiento técnico que le impregna maestría artística y un sentido religioso. Mediante este realismo surrealista su creador hace una sincera y monumental alusión a la vida del incon. cebible más allá."

4 Cf. Krickeberg, Trimborn, Müller, Zerries. Die Religionen des alten Amerika Kohlhammer, Stuttgart, 1961, p. 56:

"Verglichen mit der Menge der religiösen Altertümer, die im Staate Veracruz gefunden wurden, und mit den ausführlichen spanischen Berichten uber andere alte Völker Mexikos, wissen wir von der totonakischen Religion nur wenig..." En una obra anterior $W$. Krickeberg, la máxima autoridad sobre la antigua re. ligión totonaca, insiste en la importancia del culto de Quetzalcóatl y la celebración del dualismo. Véase Die Totonaken, Baessler Archiv VII, IX. Berlin, 1918.1925.

De la misma manera $c f$. Salvador Canals Frau, Las civilizaciones prehispánicas de América, Buenos Aires, 1956: "De la religión totonaca no es mucho lo que sabemos. Quetzalcóatl parece haber sido una de sus principales divinidades, a juzgar por la frecuencia con que su figura ha sido reproducida y especialmente en el Tajín." p. 218 .

También Henri Lehmann: Les Civilisations Precolombiennes, P.U.F., 1977: "La plupart des objets totonaques connus ont été mis au jour accidentellement, de telle sorte que nous n'avons que des notions très imprécises de cette civilisation." p. $5 \mathbf{3}$. 
que ciertamente es el mismo que el Señor Nuestro Quetzalcóatl...

Códice florentino, 148 v.5

¿Es nuestra cabeza totonaca una imagen del estado del hombre en la misteriosa región y "vagina" de la dualidad, anterior a su nacimiento? ¿O tenemos aquí la concepción análoga del ser dual del hombre, no como una unión de opuestos, una concordia discors (negro/ blanco, claro/oscuro, bueno/malo...) sino como la conjunción de lo acabado y lo no acabado?

Los códices, hasta donde me ha sido posible leerlos en las diferentes traducciones, no se refieren al hombre en cuanto la criatura "no acabada a medias".

Sin embargo, nuestra cabeza non finito puede atestiguar la existencia de una versión totonaca, todavía no descubierta, del mito de la creación de Quetzalcóatl, una versión, de acuerdo a la cual el hombre está "permanentemente inacabado", es l'homme approximatif, para usar la frase de Tristan Tzara.

O bien, nuestra cabeza no representa un estado estático, sino uno dinámico, en el cual uno de los elementos antitéticos lucha por la supremacía sobre el otro.

Si esto fuera asi, nuestra cabeza totonaca sería la descripción de una verdadera psicomaquia de la variedad mexicana, la lucha del alma humana para lograr perfección, o bien para ser destruida por la materia bruta.

Esto es, naturalmente, muy diferente de la función de lo non finito en la obra de un escultor como Miguel Ángel, tal como fue analizada detalladamente tanto en Das Unvollendete cuanto en Du.

Así, una cabeza inconclusa tal como la de San Mateo (figura 2) es la manifestación de una ideología platónica. En este caso lo non finito se usa para presentar la idea, a) que el concepto en la mente del artista, il concetto, es lo importante, es infinitamente más hermoso que la obra terminada (que es sólo un débil reflejo de él $\mathrm{y}$, por lo tanto, no merece ser extraída del todo de la materia), o bien b) que el artista es el "libertador" de una idea o concetto que se mantenía prisionera "dentro" del bloque de mármol. ${ }^{6}$

5 Versión española de Miguel León-Portilla, Quetzalcóatl, México, Fondo de Cultura Económica, 1968.

6 Esta idea era absolutamente universal en el Renacimiento en Italia. $C f_{\text {, }}$, por 
Por otra parte, puedo agregar que el San Mateo de Miguel Ángel encarna, en virtud de su carácter non finito, otra idea, mucho más moderna: la idea del arte como una señal indicativa de la actividad artística, y no solamente como una imagen icónica de un concepto, en una cultura o mito, a en la imaginación del artista individual.

De la misma manera que nuestra cabeza totonaca, San Mateo re. presenta una dualidad, pero una dualidad de carácter estético-filosófico: presenta la opacidad de la materia que coexiste con la transparencia de la representación de modo que uno de los resultados de lo non finito es que inicia una tensión y vaivén permanentes, una "metastibilidad" constante entre opacidad y transparencia, entre hylé y morphé en cuanto elementos eternamente copresentes y reversibles en una y la misma obra de arte, una variación tridimensional de lo que E. Gombrich llama el juego "naturaleza versus lienzo", al hablar de la pintura. ${ }^{7}$

En otras palabras, con Miguel Ángel y con otros artistas occidentales posteriores, lo non finito se da para reforzar la parte "obra" de la "obra de arte" y hacer que el proceso creativo pase a primer plano "en per sona". 8

ejemplo, Anthony Blunt, Artistic Theory in Italy, 1450-1600, Oxford, Clarendon Press, 1962 p. 74: " "an unfinished figure like St. Matthew gives the impression that it is all in the block and that one could just knock off the superfluous marble and reveal the complete statue" "Como apoyo en la literatura de la época, Blunt cita el famoso soneto de Miguel Ángel, en el cual la mano, obediente al concetto en la mente del artista se dice que logra el rinascimento del concetto bello ence rrado en el mármol.

Esto, naturalmente, combina entre sí las dos direcciones de la idea neoplatónica: cualquier espectador que tenga el concetto en su imaginación puede "retirat el mármol superficial', de la misma manera que lo hace el artista ( $y$ esto, inciden. talmente señala una interesante teoría de comunicación artística inherente al pensamiento de Miguel Ángel: la teoría de la posible reconstrucción "hermenéutica" de la obra de arte non finito por el espectador y la necesidad de tal reconstrucción, que justifica el estado non finito). Por el contrario, el concetto no es so. lamente subjetivo, sino que también está prisionero en el mundo de la materia: la obra del artista es meramente para ayudar a esta aletheia

$7 \mathrm{Cf}$. Art and Illusion, Princenton University Press. Sobre la "metastabilidad" del juego perceptivo, véase $\mathrm{mi}$ artículo: "The metastability of signs/metastability as a sign", Semiotics 28-1/2, 1979, pp. 83-105.

8 Véase el artículo de Gantner en Das Unvollendeté, también el de Gerd Schiff; en $D u$. Wittkower tiene algunas agudas consideraciones sobre el tema en "Individualism in Art and Artists: A renaissance Problem" Journal of History of Ideas (July-Setp. 1961) pp. 291-303: "The intentional non finito requires a new form of self analysis and interspection, for the artist has to develop a sophisticated control 
DOI: http://dx.doi.org/10.22201/iie.18703062e.1983.52.1200

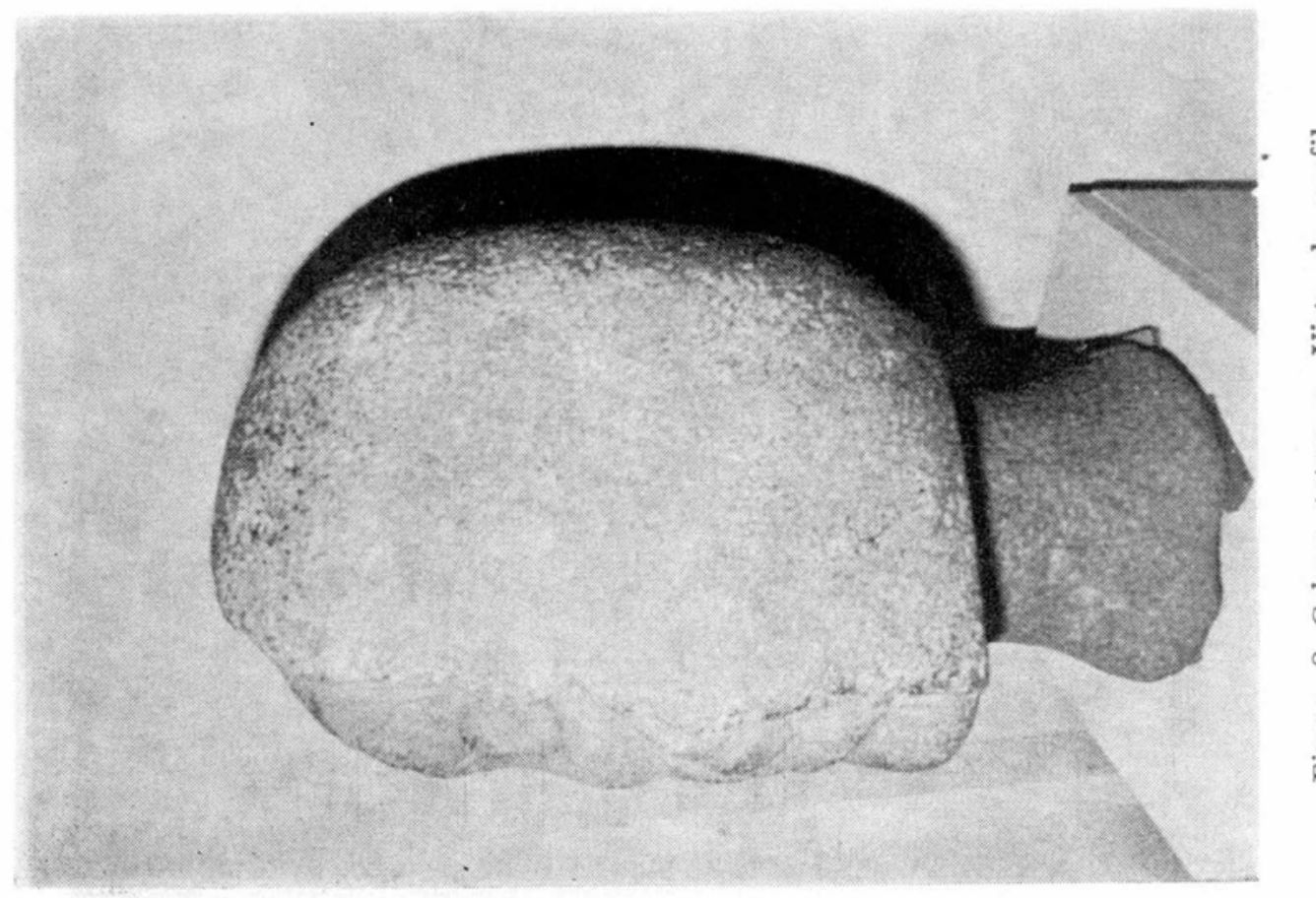

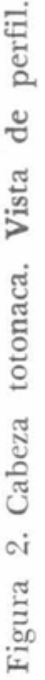

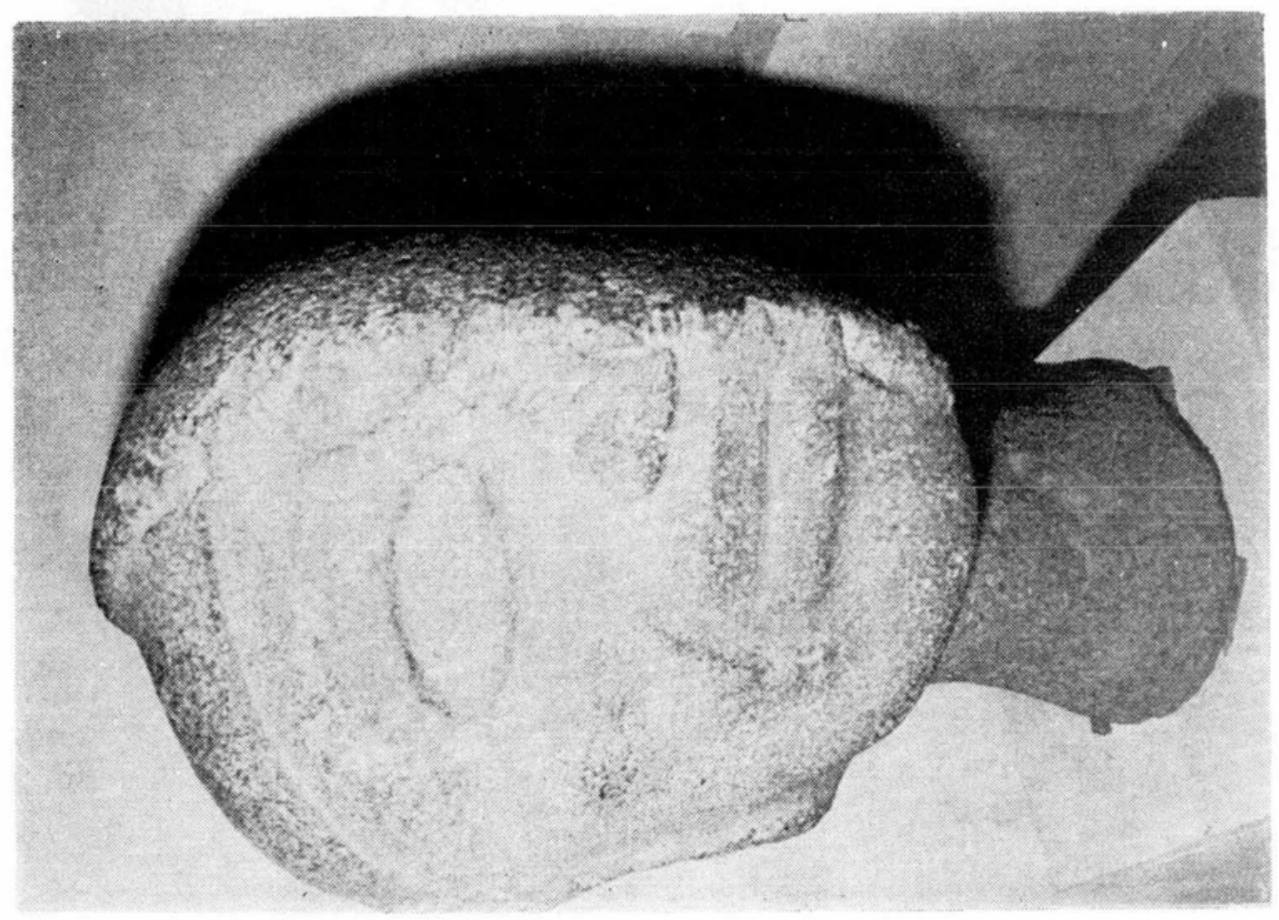

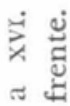

$\exists$ 음

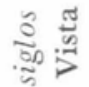

芯

ฐี

䒿

$\frac{0}{0}$

รู $\frac{0}{0}$

ठึ.

-

总总 


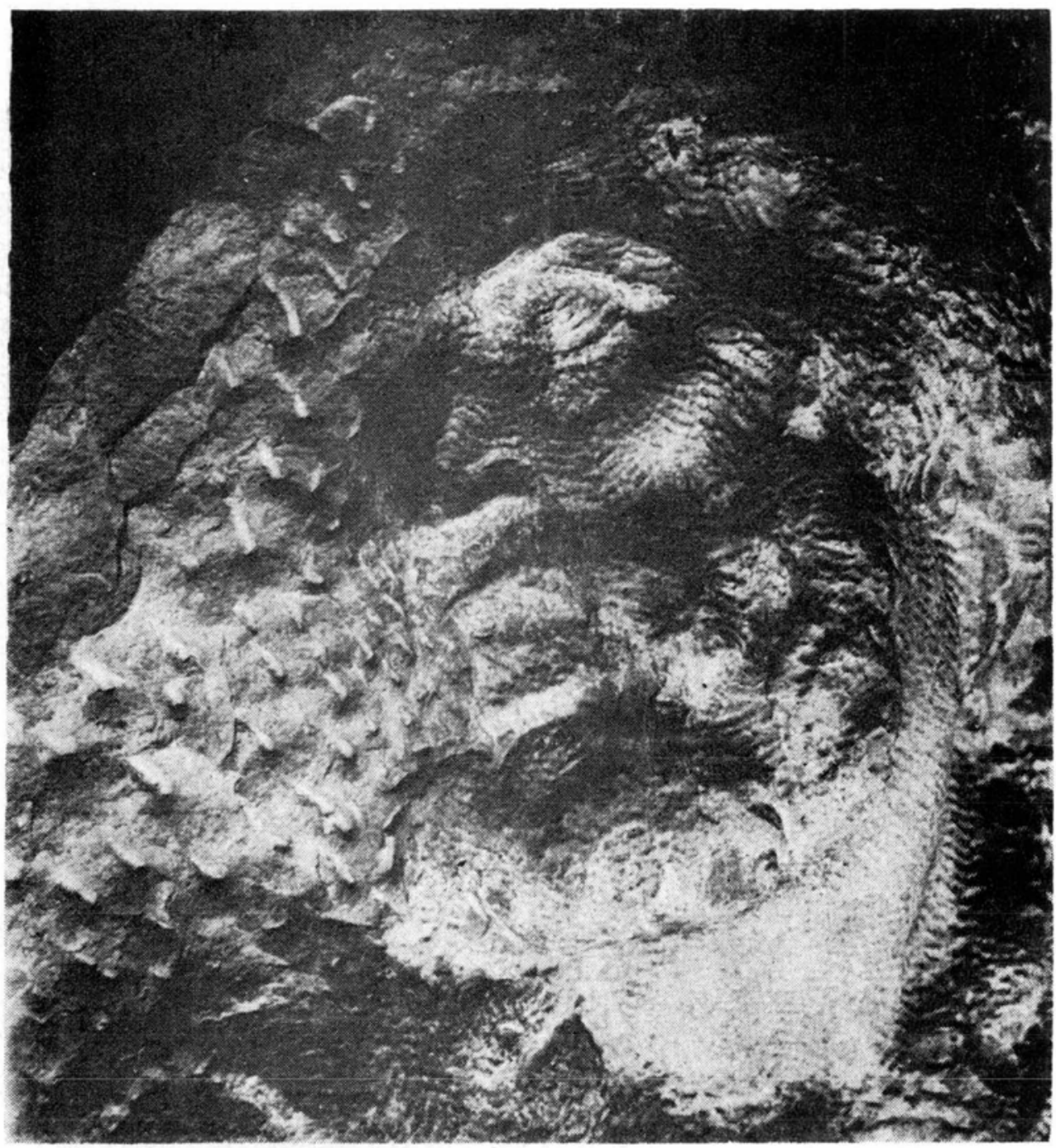

Figura 3. Miguel Ángel. Cabeza de San Mateo. 


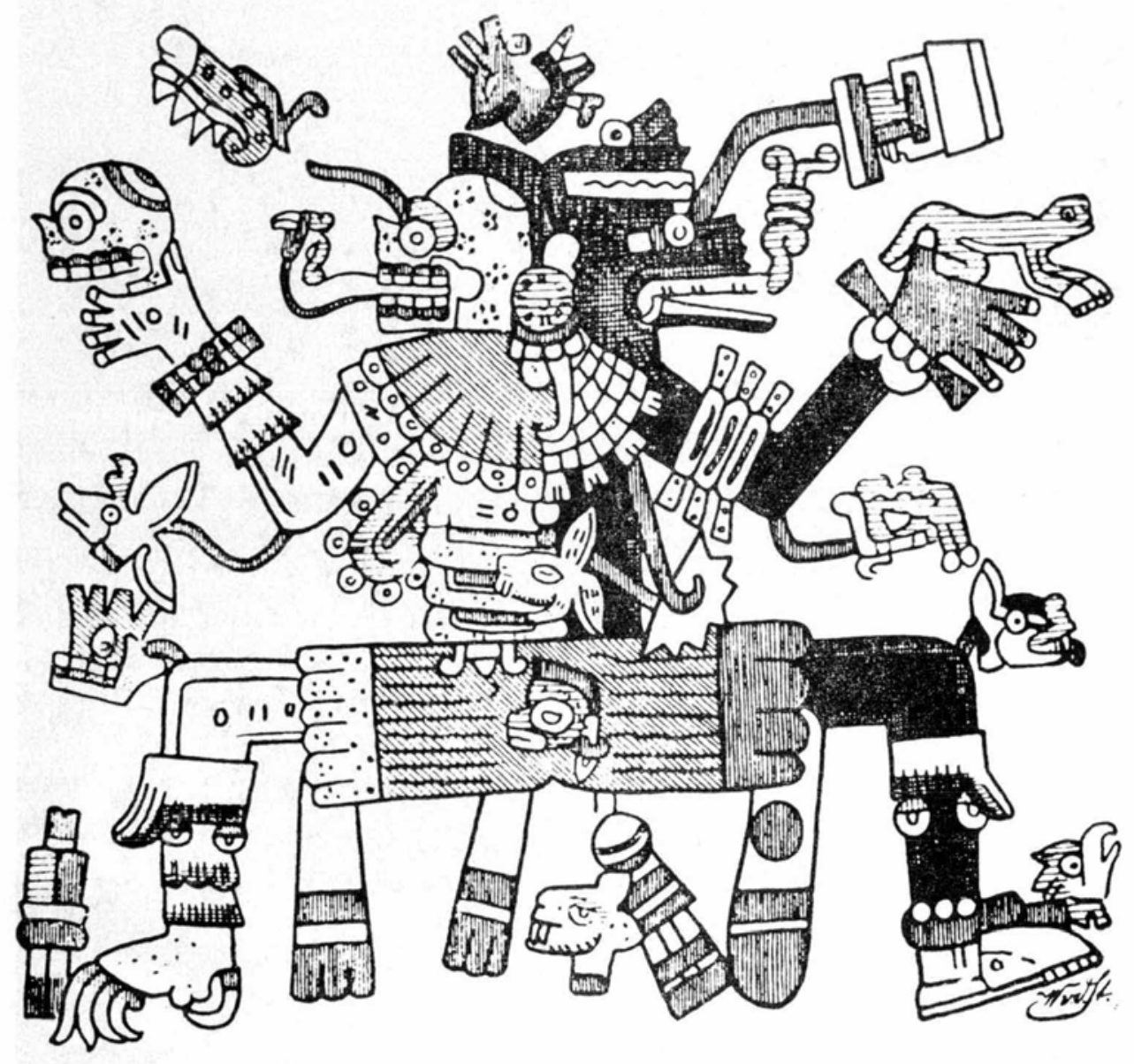

Figura 4. Quetzalcóatl como dios de la vida y de la muerte. Codex Vaticanum 3773. P1. 75. 


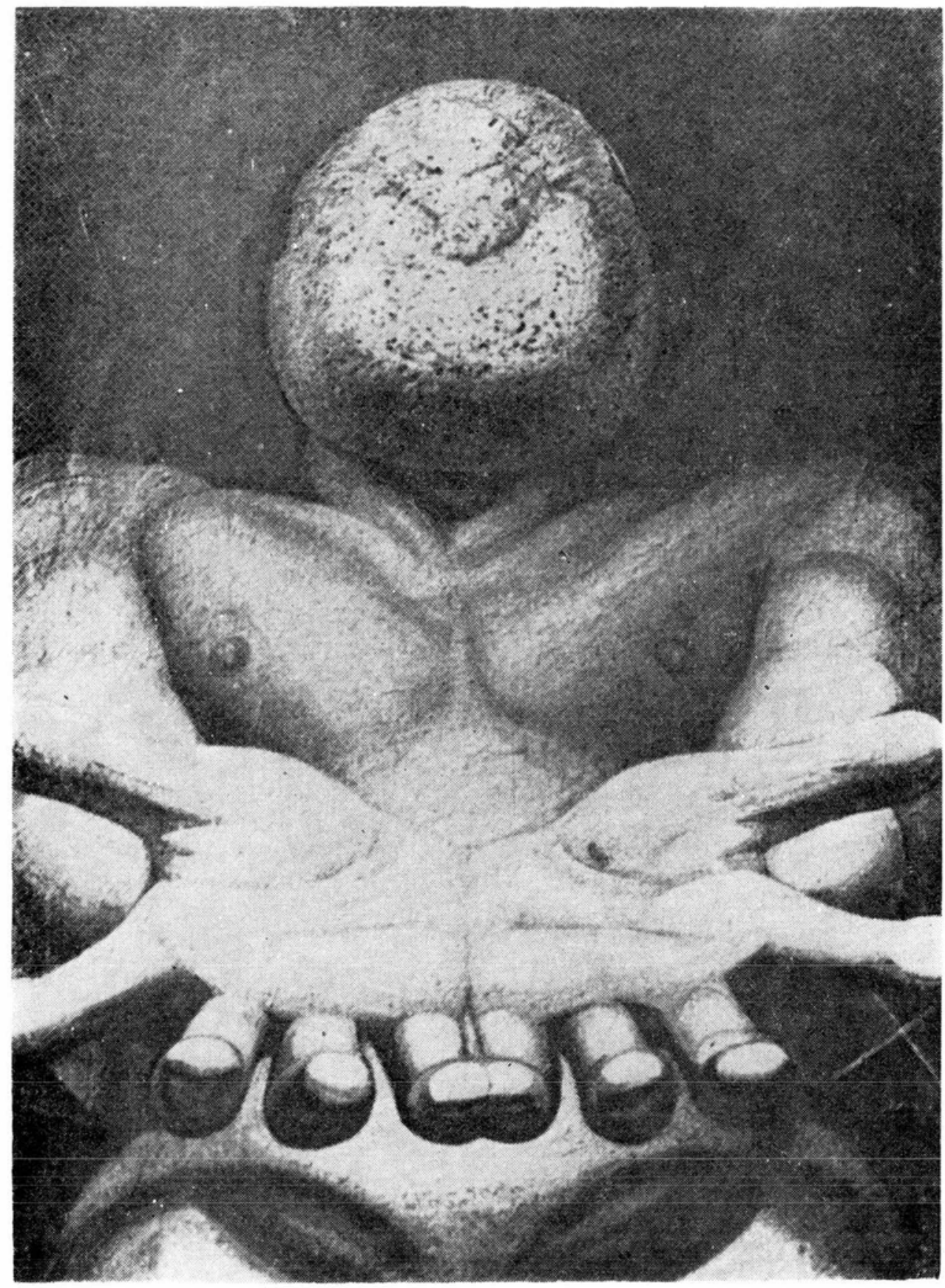

Figura 5. David Alfaro Siqueiros. Nuestra imagen actual. Museo Nacional de Arte Moderno. México. 
Naturalmente que no es esta la función de lo non finito en la cabeza de Jalapa. En ésta, la función es exclusivamente una representación del dualismo religioso y de una psicomaquia.

En realidad, la cabeza totonaca no es la única pieza de iconografía en la cual se representa el dualismo mexicano. La lucha entre sol y sombra se celebra en toda la región totonaca, incluso en arquitectura. Así, Fernando Gamboa escribe de la pirámide de El Tajín, que sus curiosos nichos "servaient à donner la sensation de clair-obscur, symbolisant ainsi le mouvement cosmique fait d'ombre et de lumière, de mort et de vie... L'obsession de l'ombre et de la lumière est encore à l'origine des délicates combinaisons de greques et de bas reliefs..." 9 de la pirámide.

Por otra parte, el dualismo en el alma del hombre que simboliza nuestra cabeza de Jalapa, no es sino el reflejo del dualismo en el dios mismo. Quetzalcóatl, como lo habíamos anotado ya, es "el dios de la dualidad":

El dios celestial se llama Señor de la dualidad

y su comparte se llama Señora de la dualidad, Señora celeste.

Quiere decir: [...]

De allá cae nuestro destino,

cuando es puesto,

cuando se escurre el niñito.

De'allá viene su ser y destino;

en su interior se mete:

lo manda el Señor de la dualidad... .

Códice matritense de la Academia de la Historia, Fol, 176 r,10

Otros textos parecen incluso atribuir una dualidad sexual a Quetzalcóatl. Así en el Códice Florentino aparece el siguiente pasaje:

self analysis and interspection, for the artist has to develop a sophisticated control of the act of creation... The non finito may be due to a deliberate decision to bring the creative process to an end at any moment of the artist's choice, so that the torso, the half-finished picture, the sketchy execution are the finished products." (p. 302). Un reconocimiento de la importancia de lo non finito deliberado en el siglo $x x$, bien puede haber llevado a la teorfa de Heidegger del objeto de arte como el indicio de una lucha entre el artista y die Erde ó hylé, vista como una opacidad activa.

9 Chefs d'oeuvres de l'art Mexicain, (Catal du Ministère d'Etat. Affaires Cul. turelles. Paris, Avril-Juin 1962), p. 196.

10 M. León-Portilla, op. cit, p. 32. 
Así es en verdad,

fue por merecimiento del señor Quetzalcóatl,

el inventor de los hombres,

el hacedor de los seres humanos....

que es Señor y Señora de la dualidad.

Así se trasmitió la palabra....

Códice Florentino, fol 120 r.11

La dualidad de Quetzalcóatl se ha representado muchas veces en la iconografía de los códices, aunque no mediante el contraste entre lo finito y lo non finito.

De esta manera, en el Códice Vaticano (figura 3) encontramos a Quetzalcóatl en la forma de un dios con dos cabezas, cuyo cuerpo es mitad negro, mitad blanco. Según Seler el dios negro es el dios de los vientos y de la vida, mientras que la mitad de dios blanco es el dios de la muerte y de la tierra, dentro de la cual se entierran los huesos antes de resurgir una vez más a la vida durante la resurrección, cuando Quetzalcóatl "se sangra" sobre ellos.12

Sin embargo, de ninguna manera parece innegable que nuestra cabeza totonaca sea una versión totonaca del dios Quetzalcóatl: su sonrisa es demasiado humana, su boca demasiado sensual, su expresión demasiado benigna. De serlo, sería una representación única del dios, difícil de encontrar en alguna otra parte de Mesoamérica.13

Quisiera concluir este estudio señalando una posible influencia de "mi" cabeza totonaca en la iconografía de la pintura mexicana moderna.

En 1947, el gran muralista mexicano, David Alfaro Siqueiros pintó Nuestra imagen actual (figura 4), que muestra una figura humana con las manos extendidas y cuya cabeza es una enorme piedra porosa, sin boca, sin ojos, sin nariz.14

11 Ibid., p. 19.

12 Véase Seler, Eduard "Das Hauptmythos der mexikanischen Stämee', Ges, Abhandlungen zur Amerikanischen $\$ p$ rach- $u$ Altertumskunde. 5 vols. Ascher $u$. Co. Behrend u. Co., Berlín, 1902-1929, t. IV, pp. 98-155.

$13 \mathrm{El}$ único otro ejemplo de non finito que pude encontrax en los museos mexicanos, se encuentra también en Jalapa. Está reproducido en la Historia general del arte mexicano: época Prehispánica. $\mathrm{R}$. Flores.Guexrero. México/Buenos Aires., F.ả. Hermes, 1962, Iám. 121. Se describe como "posiblemente inconclusa" pero no se compone de una mitad no terminada yuxtapuesta a una terminada como la cabeza tema de nuestro estudio. La no terminación puede ser accidental,

14 Respecto a Nuestra imagen actual véase Justino Fernández, Arte moderno y 
Aunque Siqueiros no dijo nada sobre su fuente de inspiración, no parece inverosímil que la cabeza de Jalapa le haya dado la idea para Nuestra imagen actual. De hecho, la cabeza inconclusa de Siqueiros no es diferente de la totonaca, vista de atrás o de perfil (figura 5). El simbolismo del cuadro puede estar relacionado con el miedo a la guerra atómica y la terrible mutilación de los seres humanos durante el bombardeo de Hiroshima, como tienden a creer algunos críticos.

Sin embargo, también pudo haber sido inspirado por nuestra cabeza totonaca, puesto que, como la mayoría de los muralistas mexicanos, Siqueiros sintió, con frecuencia, la necesidad de volver a las raíces precolombinas de su pueblo y a la mitología e iconografía de las razas indigenas. De este modo, puede ser que la cabeza de Jalapa influyera en el simbolismo de Nuestra imagen actual. El triunfo de lo non finito parece ser su verdadero tema.

No obstante, este simbolismo es doble. Por una parte, tenemos aquí la anulación de la dualidad que se celebraba en las épocas tolteca y azteca, la destrucción de la psicomaquia, pero no a favor de una victoria del lado "luminoso" del hombre. En la época de la barbarie moderna es lo oscuro, la sombra "atómica", la que ha vencido. Falto de escrúpulos, to non finito se apodera de toda el alma del hombre y lo deja "sin cara".

Por la otra, como lo non finito de Miguel Ángel, la imagen de Siqueiros tiene un aspecto reflexivo, nos dice algo sobre el arte mismo. Corresponde a la postura fuertemente anti-abstracción que tomó el artista, comprometido como estaba en aquel momento en la defensa del realismo socialista figurativo.

La pintura de Siqueiros, bien sea que haya sido inspirada por la escultura de Jalapa, o no, es el símbolo del carácter absolutamente inconcluso, fragmentario, del hombre moderno en la civilización capitalista moderna.

También es, en cuanto a lo que la obra de arte dice de la obra de arte misma, un símbolo del carácter absolutamente autoalienado del artista abstracto moderno, visto desde el punto de vista de un pintor figurativo militante.

contemporáneo de México. Imprenta Universitaria, 1952, pp. 401.403. Cf. también los escritos del propio siqueiros sobre arte, especialmente una serie de ensayos que se publicaron en el periódico Excélsior bajo el título de "Crítica a la Crítica de Arte", enero 18, 24 y 31 de 1950. 


\section{RECONOCIMIENTOS}

E1 autor desea expresar su agradecimiento a la maestra Cecilia Tercero del Departamento de Letras Alemanas de la Facultad de Filosofía y Letras de la UNAM por su traducción de este artículo, y a la doctora Nelly Gutiérrez Solana del Instituto de Investigaciones Estéticas de la UNAM, por su ayuda bibliográfica respecto al dualismo y a la religión totonaca.

Asimismo debo mi agradecimiento a la Comission for Basic Research de la Academia de Ciencias de Israel, cuya subvención para la inves. tigación hizo posible este ar tículo. 